\title{
LAS FRONTERAS DE ESPAÑA EN EL SIGLO XVIII. ALGUNAS CONSIDERACIONES
}

\author{
Miguel Ángel Melón Jiménez \\ Universidad de Extremadura
}

\begin{abstract}
Resumen. A partir de la entronización de la dinastía Borbónica en España se advierte una creciente preocupación de las autoridades por conocer los territorios periféricos de la monarquía. En el ámbito económico, y producto del deseo de captar los ingresos considerables que el tráfico de mercancías generaba en concepto de rentas de aduanas, las fronteras se vieron sometidas a un proceso de información continuo y a una estrecha vigilancia. Se dieron cita en estos cometidos los dependientes de la Hacienda y el Ejército, a fin de intentar contener el contrabando y combatir las consecuencias sociales de las conductas trangresoras en que incurrían los súbditos aplicados a esta actividad. El resultado, en términos documentales, fue una abundante información que permite conocer a fondo las demarcaciones fronterizas y los comportamientos que las diferenciaban de los restantes territorios que formaban el Imperio español.
\end{abstract}

Palabras clave: fronteras, aduanas, Hacienda, Ejército, contrabando.

\begin{abstract}
Since the arrival to the throne of the Borbonic dynasty in Spain is notice an increasing preoccupation of the authorities to know the borders of the monarchy. In the economic area and due to desire to earn the considerable income that generated the traffic of merchandize for rents of customs, the borders me submitted to a constant process of information an to a narrow alertness. The employees of the tax authority and the army took part in these assignments to contain the smuggling and to attack the social effects of it. The documentary result was an abundant information that allows to know the border demarcation and the behaviours that differentiated them from the remaining territories that formed the Spanish empire.
\end{abstract}

Keywords: borders, customs, Spanish Royal Treasury, army, contraband.

EN PALABRAS de uno de los mejores especialistas en su estudio, Daniel Nordman, la frontera constituye una armadura, un conjunto espacial, militar, económico y fiscal, 
administrativo, cuyos caracteres varían en función del espacio y del tiempo ${ }^{1}$. En términos identitarios, se presenta como un todo, que es producto de unas determinaciones geofísicas y de una evolución histórica, en ocasiones sometida a presiones continuas por parte de los gobiernos, etnias o grupos sociales que en ella convergen. Los Estados, a través de su diplomacia, han tratado de resolver o amortizar los inevitables choques fronterizos y garantizarse la ausencia de confrontaciones futuras, acudiendo para ello a la precisión delimitatoria y a la suscripción de acuerdos de colaboración que garantizaran la seguridad de sus relaciones internacionales de carácter territorial.

Aunque estos espacios tienen un origen básicamente determinado por cuestiones militares y permanecen asociados a la idea de conflicto, peligro o trasgresión, lo que convierte a la frontera militar en arquetipo, interesa al objeto de lo que en las páginas siguientes se expone la denominada frontera de los economistas, de posterior concreción en el tiempo, pero cuya importancia no resulta menor a la hora de concebir las relaciones entre dos reinos. Se identifica ésta con la idea de la protección aduanera, lo que traslada el concepto desde el campo de la geopolítica al dominio civil, puesto que la política comercial puede utilizarse como arma por parte de los gobiernos imponiendo medidas restrictivas para la importación y que favorezcan la exportación, conforme a los presupuestos de las doctrinas económicas de los siglos XVII y XVIII ${ }^{2}$ que alumbran el surgimiento de un Estado, relativamente cerrado, dominado por un mercantilismo cuya función histórica, además de convertirlo en un cuerpo económico autónomo y de haber liberalizado el comercio interior, consiste en establecer "fronteras aduaneras hacia el exterior, que tienen en realidad una puerta abierta, por lo general, pero que son vigiladas y controladas celosamente desde el punto de vista de la balanza comercial"3 y que actúan como auténticas "puertas de la vida y de la muerte"4 cuando de transacciones mercantiles se trata.

1 Trabajo enviado el 25/01/2010 y admitido para su publicación el 17/03/2010.

NORDMAN, D.: “La formation de l'espace français", en REVEL, J. (Dir.): Histoire de la France. L'espace français, París, 2000, pp. 39-209. Los geógrafos y tratadistas del Derecho precisaron tiempo atrás algunos de los aspectos esenciales para definir las fronteras. Jacques ANCEL (Geographie des frontières, 1938) señala que, entendidas como necesidad vital, surgen cuando dos grupos humanos se encuentran y para evitar conflictos, pero que sólo en el transcurso de los siglos adquirieron estabilidad y permanencia; según Paul FAUCHILLE (Traité de Droit international public, 1925), allí donde termina el dominio de un Estado para empezar el de otro, existe un límite: dichos límites son las fronteras.

2 NORDMAN, D.: Op.cit., pp. 42 y ss.

3 HINTZE, O.: "Esencia y transformación del Estado moderno", Historia de las ideas políticas, Madrid, 1968, pp. 293-323. Presupuesto implícito en los acuerdos comerciales suscritos por los principales estados europeos con la monarquía borbónica desde su llegada a España, cfr. A. del CANTILLO: Tratados y declaraciones de paz y de comercio que han hecho con las potencias extranjeras los monarcas españoles de la Casa de Borbón. Desde el año de 1700 hasta el día. Madrid, Imprenta de Alegría y Charlain, 1843.

4 ANGULO MORALES, A.: Las puertas de la vida y la muerte: la administración aduanera en las provincias vascas, 1690-1780. Bilbao, 1995. 
El territorio fronterizo, merced a la deriva fraudulenta que suelen experimentar los intercambios y transacciones que en él se producen, o bien a raíz de transgresiones sociales acaecidas en circunscripciones próximas o alejadas, cuyos autores se desplazan hasta allí en busca de un refugio seguro, alberga por lo general una población de tintes marginales, lo cual conlleva la asunción de una inseguridad y unas formas de disidencia que los Estados aceptan en beneficio de la cohabitación internacional, pero también para preservar a veces una paz interior muy frágil en sus márgenes. Es posible hablar, por tanto, y la historia aparece repleta de episodios que lo demuestran, de un espacio marginal "relativamente" controlado por las autoridades, pero con unas tensiones en su seno que en cualquier momento pueden hacer saltar por los aires el equilibrio inestable sobre el que descansa y los acuerdos tácitos que posibilitan la cohabitación. A ambos tipos de frontera y a las actuaciones que la Administración Borbónica plantificó para gestionarlas y vigilarlas durante el siglo XVIII se refiere el contenido de este trabajo.

\section{Conocer y delimitar la periferia. Algo más que una necesidad del Estado Moderno}

Una de las cuestiones básicas en el estudio de las fronteras pasa por definirlas en perspectiva histórica y bajo la amplia gama de posibilidades que ofrecen sus límites; es decir, considerarlas como un hecho preciso que posee atribuciones y rasgos distintivos específicos. Supone, por otro lado, un encuentro o punto de conexión de elementos palpables y visibles provenientes de instituciones y espacio construido, por lo que ha de tenerse en cuenta que nada en el medio físico impone necesariamente una frontera, puesto “qu'il faut dans tous les cas une convention, une décision, commune ou non à tous les voisins intéressés, pour que la frontière, perceptible dans un paysage, soit enfin acceptée comme telle"s. Sin olvidar, en última instancia, el hecho fundamental que las define y que genera una información que fluye en sentido bidireccional: el de conformar un territorio, discutido y discutible, en el que dirimen sus desavenencias los Estados y donde marcan, de común acuerdo o por imposición, los ámbitos de sus respectivas soberanías.

Sucede de ese modo porque la frontera constituye una realidad heterogénea donde convergen flujos de diferente naturaleza que, lejos de los consabidos particularismos localistas, facilitan una adecuada percepción de la universalidad que en sus límites confluye. Su espacio real, aquél sobre el que proyecta su influencia, no suele

5 NORDMAN, D.: Frontières de France. De l'espace au territoire (XVI $-X I X^{e}$ siècle), París, 1998 , p. 11. 
corresponderse con el cartografiado en los mapas, planos y dibujos que la representan y se esmeran en trazar cuantos agentes intervienen en los procesos delimitatorios. Los estudios dedicados a esta materia quedarían incompletos si se circunscribieran a detectar el tránsito de personas y productos que registran las contabilidades de los establecimientos aduaneros y no supiéramos qué ocurre en sus lugares de procedencia, durante su transporte, y hasta que llegan a su destino final. De ahí la conveniencia de precisar con exactitud su ubicación última, que no se encuentra exactamente donde la emplazan los accidentes naturales, los tratados, las fortalezas y las aduanas, sino donde la sitúan los hombres con sus movimientos y decisiones. Un texto de Nordman resume de manera apretada algunos de sus muchos significados y deja abiertas sugerentes vías de investigación sobre el particular:

La frontière, ensuite, est le siège d'institutions, d'administration douanières, administratives, militaires. Dans les rapports qui se nouent entre occupation et souveraineté, des forces sociales, des acteurs, du haut en bas de la pyramide sociopolitique, font la frontière: intendants, hommes d'Etats, militaires, diplomates la proposent, la définissent, la tracent, l'inventent. Il n'est pas posible de dire qu'une frontière a été tracée: ce sont des acteurs qui la tracent. Ils font de la frontière un ensemble de lieux et de conduites politiques qui ne sont pas exclusivamente voulues d'en haut, car elles résulten du jeu complexe des relations verticales entre pouvoirs et administrés. Ceux-ci ne sont jamais entièremen passifs: ils acceptent, discutent, modèlent, façonnent. Des commisaires envoyés sur places les consultent, ou font semblant de la faire. De simples paysans -les principaux habitants des communautés villageoises-, interrogés, décrivent les terres qu'ils connaissent, dénoncent les impôts excessifs qu'ils supportent, désignent les lieux de justice dont ils dépendent ou les marchés qu'ils fréquentent ${ }^{6}$.

La frontera es, por tanto, una zona, y no una línea, articulada en torno a un conjunto de lugares centrales que, de un lado y otro de la línea divisoria, desarrollan una interacción en diversos ámbitos y cuyas trayectorias discurren a menudo en direcciones opuestas a las directrices marcadas por los respectivos Estados que en ella coinciden. Dichos enclaves desarrollan unas dinámicas propias sobre la base del ininterrumpido feedback que se establece entre la autoridad central y los poderes locales que gestionan el territorio en que se asientan, factor que a su vez introduce un elemento de primer orden en el análisis, relativo a las relaciones de la capital del Estado y sus fronteras, que depende en buena medida del emplazamiento de éstas. Una relación que es compleja y variable y que, en lo concerniente a España y al denominado modelo

6 NORDMAN, D.: "La frontière: notions et problèmes en France (XVe-XVIIIe sieclè)", Lo spazio sabaudo. Intersezioni, frontiere e confini in età moderna, Milán, B.A. Raviola Ed., 2007, pp. 19-30. 
español ${ }^{7}$, su capital, centro político y geográfico al mismo tiempo, debe controlar durante parte de la Edad Moderna no sólo sus fronteras peninsulares desde la distancia, sino las de una parte sustancial del mundo mientras mantuvo su imperio.

Su proceso de constitución rebasa los límites seculares y adquiere todo su sentido contemplado en una perspectiva espacio-temporal que permite sopesar los estadios que han experimentado las relaciones entre países limítrofes. En lo concerniente a las fronteras peninsulares, excepto para Gibraltar, arranca de la Edad Media y pospone su culminación hasta la época Contemporánea, sucediéndose en él una serie de etapas que exigieron de toda la capacidad de cuantos se ocuparon en las tareas del difícil arte de delimitar (boundary making) para llevarlo a buen término. Este proceso toma forma y se sustenta sobre una serie de tratados internacionales que sancionan una realidad preexistente, antigua o inmediata, y su plasmación sobre el papel exige previamente del concurso de minuciosos complementos para concretarlo, a fin de garantizar una estabilidad lo más duradera posible en sus extremos y evitar conflictos en el futuro, si es que se pretende hacerlo: actas demarcatorias, protocolos para cuestiones específicas, mapas, acuerdos, actos de amojonamiento y trazado, ofrecen una información exhaustiva de las circunscripciones a las que se refieren al participar en ellos militares, diplomáticos, geógrafos, cartógrafos, topógrafos y personas entendidas de los lugares que informaban de usos y servidumbres observados desde tiempo inmemorial $^{8}$.

Las primeras concesiones de la frontera con Portugal se encuentran en el Tratado de Badajoz de 1267, y en 1297 el Tratado de Alcañices precisa la línea divisoria. La anexión del vecino reino en 1580 obligó a abordar de modo diferente el problema, y la Guerra de Restauración la consolidará mediante un sistema de fortalezas, cuya delimitación se fijará en el Tratado de Lisboa de 1668, posteriormente confirmado en los de 1713, 1763 y 1783. El Tratado de Badajoz (1801) costó a Portugal el enclave de Olivenza, fijándose la frontera entre España y Portugal, excepción hecha de la parte correspondiente a dicho término, en los Tratados de límites de 29 de septiembre de 1864 y 4 de noviembre de 1866, en el Acta general de 1 de diciembre de 1906 y en el Convenio firmado el 29 de junio de $1926^{\circ}$. El trazado que rige en la actualidad para la de Francia arranca de la firma de tres convenios: 2 de diciembre de 1856, referido

7 NORDMAN, D.: Ibidem.

8 Sobre este particular me remito al libro, ya clásico, de J.M. CORDERO TORRES: Fronteras hispánicas. Geografía e historia. Diplomacia y administración. Madrid, 1960, y a las consideraciones de D. NORDMAN, a propósito de la cartografía, como empresa indisociable de la afirmación del poder; aspecto éste que en el siglo XVIII se manifiesta en España en toda su extensión.

9 RAVENTÓS y NOGUER, M. y OYÁRZABAL VELARDE, I.de: Colección de textos internacionales. Barcelona, 1936. 
al sector pirenaico del océano a Aragón; 14 de abril de 1862, para la parte oscense y leridana hasta Andorra, y 26 de mayo de 1868, desde Andorra al Mediterráneo. Hasta entonces se mantenían en vigor los acuerdos sellados en la Paz de los Pirineos (16591660), posteriormente confirmados en los dos Tratados de límites de 12 de noviembre de 1764 y 27 de agosto de 1785, y en 1795 y 1814. En cuanto a la de Gibraltar, se estableció en virtud de los Tratados de Utrecht, de 13 de julio de 1713.

En España, desde la llegada de Felipe V, se detecta una creciente preocupación por controlar los resortes del Estado ${ }^{10}$; empresa en la que la gestión de las aduanas que definían las fronteras comerciales, en manos de asentistas, centraría pronto la atención de los gobernantes. La fecha clave al respecto viene marcada por la suspensión de pagos decretada el 21 de marzo de 1739, año en que se inician las grandes reformas de la centuria en materia hacendística, "se pone fin a un sistema de finanzas públicas dominadas por el negocio privado", y se asiste al "último acto de una historia cuyos orígenes, en el caso español, datan de 1557"11. Dicha crisis "forzó a la cabeza de la monarquía a optar decididamente por aquel tipo de organización en el que la gobernación tenía prioridad sobre la justicia”, en la pugna que abiertamente venía planteándose desde mediados del siglo XVII y que la irresolución del primer Borbón en algunos temas había impedido que se decantara de modo definitivo en una u otra dirección ${ }^{12}$. El segundo hito se encuentra, a mi modo de ver, en 1784, al someter desde ese año en adelante a la frontera y a los territorios con los que mantenía conexiones a una vigilancia intensiva, sistemática y continua, que desembocará en una propuesta de militarización del orden público, dado el componente de marginalidad que los tráficos ilegales de mercancías habían generado en sus confines. Ambas medidas aportarán datos esenciales para comprender las diversas facies que concurren en un antemural tan necesario frente a un reino, el de Portugal, enemigo y segregado de la Corona, en palabras de Pedro Rodríguez Campomanes ${ }^{13}$, y ante dos tradicionales potencias rivales de la Monarquía Hispánica, como eran Francia e Inglaterra.

Existe un antes y un después de estas fechas perfectamente definido en cuanto a la preocupación de la monarquía por la periferia real del Estado, lo que a su vez generará un cúmulo de información adicional cuyo tratamiento permite conocer con

10 Miguel RODRÍGUEZ CANCHO, insistió tiempo atrás sobre esta circunstancia en La información y el Estado. La necesidad de interrogar a los gobernados a finales del Antiguo Régimen, Cáceres, 1992.

11 FERNÁNDEZ ALBALADEJO, P.: "El decreto de suspensión de pagos de 1739: análisis e implicaciones", Moneda y Crédito, 142, 1977, pp. 51-85.

12 FERNÁNDEZ ALBALADEJO, P.: Fragmentos de monarquía. Trabajos de historia política. Madrid, 1992, p. 456.

13 Memorial Ajustado hecho en virtud de decreto del Consejo del expediente consultivo que pende en él, en fuerza de Real Orden, comunicada por la Secretaría de Estado, y del Despacho Universal de Hacienda, con fecha en San Ildefonso de 20 de julio del año de 1764, Madrid, 1771, fol. 48v. 
detalle un espacio relativamente difuso hasta entonces, del que llegaban con frecuencia noticias sesgadas o deliberadamente confusas por parte de quienes lo habitaban, y que con anterioridad había preocupado más en términos políticos y militares, pero menos en sus aspectos económicos, tal como lo haría a partir de entonces y en función del volumen creciente de negocios que en él se producían, tanto en su vertiente legal, como en la ilícita. Ha de advertirse, no obstante, que hasta la década de los ochenta el Estado recabó información sobre la frontera y el sistema de vigilancia aduanero a iniciativa propia; a partir de entonces, en cambio, fue lo acontecido en dicha demarcación lo que motivó el aumento de noticias que los agentes de rentas y los militares desplazados a ella trasladaron a sus respectivas dependencias de la Hacienda y del Ejército, obligados en gran medida por el torbellino de voluntades indómitas que allí se desencadenó. Este largo y complejo proceso de estructuración, inspección y vigilancia contribuyó a modelar la fisonomía de estos territorios y a consolidar una particular idiosincrasia que los distinguiría de los demás.

Las fuentes documentales a disposición del estudioso de las fronteras son de una riqueza informativa extraordinaria, y la mejor prueba de la prioridad que la monarquía borbónica les dio es la infinidad de legajos conservados en los archivos sobre el particular. Las diferentes secciones que custodian fondos sobre aduanas albergan los expedientes relativos a las del reino, a los productos que transitaban por ellas, a los reglamentos que debían observar los funcionarios, a los aranceles o tasas que se pagaban, y a las inspecciones o visitas que se realizaron en el siglo XVIII. En ellas se conserva, casi al completo, infinidad de memoriales sobre su estado e informes de los valores de rentas redactados por los dependientes de Hacienda durante sus visitas, en los que sus autores dejaron constancia del estado en que unas y otros se hallaban, así como de la situación del personal civil encargado de su gestión o vigilancia. Por otra parte, secciones como la correspondiente a Guerra Moderna, del Archivo General de Simancas, atesoran centenares de partes de incidencias, correspondencia (pública y privada), estadillos, minutas, etc., redactados por los militares durante las comisiones que se les encomendaron para perseguir a contrabandistas y delincuentes de 1784 en adelante, que complementan la vertiente social del problema que subyace bajo la siempre fría información procedente de los aspectos contables.

Del análisis de tan ingente masa documental puede colegirse la existencia de tres períodos claramente diferenciados durante el siglo XVIII en materia de administración y vigilancia aduanera. El primero se extendería entre el advenimiento de la monarquía Borbónica y 1739, dándose en él una serie de pasos de cara a la futura reestructuración a que se vería sometido el sistema aduanero español, cuyas rentas y establecimientos pasarían de ser gestionados por asentistas extranjeros a administrarse directamente por la Hacienda; el segundo abarcaría desde esas fechas hasta 1784, procediéndose 
en dicha etapa a un proceso de adaptación y reorganización y a un reconocimiento de los territorios fronterizos para asegurar una eficiente cobertura fiscal de los mismos. La tercera fase comenzaría en 1784 y se prolongaría hasta 1800, coincidiendo con el principio y el final de la movilización del Ejército para colaborar en tareas de orden público, vistas las dimensiones que había adquirido el contrabando y la peligrosa deriva que se estaba produciendo desde esta práctica hacia la delincuencia.

\section{La gestión de las fronteras del comercio en el siglo XVIII}

A principios del siglo XVIII los funcionarios de la Real Hacienda pensaron en las rentas generales o de aduanas como uno de los pilares esenciales sobre los que descansarían los ingresos del nuevo Estado. Confiaban en ellas para paliar la calamitosa situación económica derivada de la Guerra de Sucesión, pero también para aliviar a los vasallos de las onerosas rentas provinciales; después, y ya en pleno reformismo carolino, en la mente de hombres como Campomanes y López de Lerena se erigieron en un elemento fundamental de su pretensión por convertir a España en el gran intermediario comercial entre Europa y América. Las aduanas, tal como las definiría a principios del siglo XIX el comisionado J.M. Zuaznavar, eran los establecimientos encargados de vigilar los tráficos de mercancías en los territorios fronterizos, pero también un preciso "termómetro para graduar la protección de la agricultura, industria y comercio lícito nacionales, y el contrarresto de los extrangeros, en lugar de ser el horror del comerciante honrado y el ludibrio de una multitud inmensa de hombres ocupados en defraudar derechos complicados, excesivos, y quizá (y esto sería lo peor) arbitrarios e injustos"14. He ahí los peligros del sistema evidenciados por unos economistas que conocían a fondo la materia y las enrevesadas aristas hacia las que podía conducir una mala gestión de los resortes aduaneros encargados de canalizar en provecho del Estado el comercio exterior, tanto en su vertiente activa (exportaciones), como pasiva (importaciones), según la terminología de la época.

En pleno conflicto sucesorio, la supresión de las barreras que gravaban la libre circulación de mercancías en el interior del reino se iniciará con el auto acordado de 25 de enero de 1708, por el que se eliminaban los puertos secos de Valencia con Castilla y Aragón ${ }^{15}$. Finalizada la contienda, por real orden de 19 de noviembre de 1714 , lo eran las aduanas de Cataluña, que pasaban a considerarse "como provincias

14 ZUAZNAVAR, J.M.: Informe al Excelentísimo Señor don Martín Garay, Secretario de Estado y del Despacho Universal de Hacienda en virtud de Real Orden de 7 de abril de 1817, Pamplona, Imprenta de la viuda de Rada, 1821, p. 47.

15 Tomo Tercero de Autos Acordados, que contiene nueve libros, por el orden de títulos de las Leyes de Recopilación, Madrid, 1775. 
unidas, corriendo el comercio entre ellas libre y sin ningún impedimento". Por reales decretos de 31 de agosto y 21 de diciembre de 1717 se acordó el traslado de las aduanas interiores a "los puertos de mar de España, en donde tienen costas, y en donde no, que es en las fronteras de Portugal y Francia, en la misma frontera, en los parajes que en una y otra parte se hallen por más a propósito"16. Sabido es que estas disposiciones motivaron la inmediata protesta de las Provincias exentas y de Navarra, que consiguieron en 1722 restablecerlas. Pese a los cambios, las rentas de aduanas continuaron gestionándose por asentistas italianos, cuyo último arriendo durante el Antiguo Régimen se concertó el 1 de septiembre de 1734 en favor de Ambrosio María Andriani ${ }^{17}$. Tales movimientos debieron influir notablemente en la percepción y el ser fronterizos de los territorios afectados por estas disposiciones, en tanto que mientras los habitantes de unas demarcaciones adquirían tal condición, cesaba para otros que tradicionalmente la poseían. Y esto marcó indudablemente el discurrir de sus días y la orientación de sus ocupaciones.

Tras ese período de tiras y aflojas, el momento decisivo, ya sin vuelta atrás posible, se produjo a finales de la década de los treinta. La difícil coyuntura provocada por la suspensión de pagos de 1739 y la guerra contra Inglaterra obligaron a plantear abiertamente la viabilidad del sistema de gestión de rentas ${ }^{18}$. Por real orden de 1 de diciembre de ese año se reintegraron a la Hacienda las denominadas rentas generales o de aduanas ${ }^{19}$, otorgándose plenos poderes para sacar la reforma adelante al gobernador del Consejo de Hacienda y superintendente general de ella, Marqués de Murillo. Posteriormente, durante el tiempo que José del Campillo estuvo al frente de la Superintendencia General de Hacienda, en 1741, se consolidará el camino irreversible hacia la administración directa de las rentas, centralizada y dirigida por los intendentes provinciales en sus respectivas demarcaciones; presupuestos organizativos que asumiría el Marqués de la Ensenada. Convencidos de su extraordinaria importancia, se convertirán en los artífices de la primera gran reestructuración de esta clase de rentas, con la que pretendían, en principio, controlar la actividad diaria de las

16 Archivo General de Simancas (AGS), Dirección General del Tesoro (DGT), Inv ${ }^{\circ}$ 24, 648, expte. 21, “Aduanas de puertos marítimos y fronteras de Portugal y Franzia. Comisión al Señor Marqués de Campoflorido para que dichas fronteras se extablezcan y execute lo que se expresa".

17 Biblioteca Nacional (BN), Sig. VE/1329-26. Un análisis pormenorizado de estos arrendamientos y del sistema de gestión aduanero, en MELÓN, M.A.: "Las fronteras de la Monarquía y las aduanas de Felipe V", en SERRANO, E. (Ed.): Felipe Vy su tiempo. Congreso internacional, Zaragoza, 2004, t. I, pp. 167-199.

18 FERNÁNDEZ ALBALADEJO, P.: "El decreto de suspensión...,", pp. 51-85.

19 AGS, DGT, Inv 24, 649, expte. 27, "Rentas Generales. Copia del aviso de la Secretaría de Hacienda, con inserzión del decreto de S.M. en que manda se administren dichas rentas generales para desde $1^{\circ}$ de enero de $1740 \mathrm{y}$ da la forma en que se ha de practicar". 
aduanas y arreglar los aranceles de los partidos aduaneros ${ }^{20}$, guiados por una finalidad proteccionista tendente a salvaguardar la producción nacional de la competencia extranjera; medida que, inexorablemente, abría la puerta al contrabando, al convertir la introducción fraudulenta de mercancías en un negocio de rápidas y sustanciosas ganancias que se regía por la inapelable ley de la oferta y la demanda. Era la respuesta inmediata de una Hacienda en apuros, la "factura retardada de la crisis posbélica de comienzos de siglo, de la que, por una serie de circunstancias fortuitas, la monarquía había conseguido librarse hasta entonces"21.

A instancias de estos gobernantes, una pléyade de subdelegados de partido, administradores generales, contadores, visitadores, guardas y ministros de rentas se encargaría de engrasar y poner a punto una maquinaria de recaudación mucho más eficaz que el ya agotado sistema de arrendamientos. Los visitadores de aduanas inspeccionaban los locales donde se ubicaban, revisaban la aplicación de los aranceles y los instrumentos de medición para aplicarlos, y dejaban constancia de las prácticas comerciales que detectaban y de las mercancías que pasaban por ellas, de la situación personal de los dependientes de rentas, y de los abusos que se producían en cada una de las demarcaciones. Sus anotaciones permiten descubrir los recursos de los defraudadores y los espacios por los que se movían, si bien no con la precisión que se haría a partir de la década de los ochenta, cuando los militares se aplicaron a las tareas de vigilancia de los territorios fronterizos. Algunos ejemplos así lo demuestran.

En 1747 visitó la frontera de Andalucía y Extremadura con Portugal Esteban Pérez Delgado, empleado de la Dirección General de Rentas. El 16 de junio remitía a Madrid un primer Informe de la situación en que se encontraba aquélla, en el que daba cuenta de las prácticas fraudulentas que en tierras andaluzas y extremeñas se venían produciendo con los intercambios de mercancías a través de la frontera con Portugal ${ }^{22}$. Años más tarde, por orden de 1 de junio de 1767, se reestructuraron las rentas generales de Extremadura y se modificó su sistema de administración, encargo que se encomendó a Bernardo de Ricarte, administrador general de la renta del tabaco del reino y ministro de la Junta de Hacienda ${ }^{23}$. Ricarte actuó con diligencia, y en septiembre ya estaban acomodados los sueldos de los funcionarios a las nuevas directrices, reestructurada la administración de Extremadura, y arreglado el Resguardo que vigilaba

20 Los aranceles continuaron actualizándose durante todo el siglo XVIII. Sólo en el reinado de Carlos III llegaron a promulgarse sesenta y cuatro. AGS, Dirección General de Rentas (DGR), 2ª r., 477, Reglamentos y aranceles de aduanas (1746-1780); 472, Borradores de aranceles y relación de géneros prohibidos de las aduanas, que se aprobaría por real orden de 23 de diciembre de 1782; y 481, Arancel de diezmos de aduanas (1770-1776).

21 FERNÁNDEZ ALBALADEJO, P.: “El decreto de suspensión...”, p. 51-85.

22 AGS, DGR. $2^{a} r, 508$. "Expediente de la visita hecha a las aduanas de los partidos de Sevilla, Badajoz y Málaga (1745-1748)".

23 AGS, DGR, $2^{a} r$, 495: "Expedientes de razones de géneros de dueños no conocidos existentes en las aduanas y arreglo del Resguardo de Extremadura". 
la frontera con Portugal24. En 1767, además, se fijaron las "Reglas que se deberán obserbar imbiolablemente por los administradores de las aduanas referidas en este reglamento"25, y en 1769 se comisionaba a Fernando Costas Castillo para que averiguara el estado de las rentas generales de Extremadura desde 1750. Meses después remitía a sus superiores un amplio Informe sobre el estado del comercio de España con Portugal. Medios de mejorarle. Con algunas ydeas sobre labranza, crianza, y comercio en general ${ }^{26}$. Consta de tres grandes apartados: el primero dedicado a la extracción de moneda; el segundo, sobre el estado del comercio en Extremadura, y en el tercero expone sus consideraciones y propuestas para atajar el problema y conseguir mejoras sustanciales en los intercambios mercantiles transfronterizos.

El creciente interés por un mejor seguimiento de los tráficos de mercancías se completó con un cartografiado de la zona y con una serie de expedientes destinados a repertoriar las rutas que, abiertas por los defraudadores, atravesaban la frontera. En 1750 las autoridades de los pueblos limítrofes con Portugal remitieron al comandante general de Extremadura, Luis Portel, un informe de los caminos que existían en sus respectivas jurisdicciones ${ }^{27}$, lo que permitió a su destinatario percibir la contigüidad lineal entre regiones limítrofes, complemento de la contigüidad extensa y plena que emerge de las visitas practicadas por los administradores ${ }^{28}$. Sin fecha conocida, pero del siglo XVIII, es también la "Descripción del reconocimiento hecho en todos los pueblos, caminos, veredas, ríos, arroyos, puentes, vados, bosques, y Sierra de Gata, de la frontera de Extremadura con el Reyno de Portugal desde la margen derecha del río Alagón hasta su encuentro con el Tajo"29. Como extraordinario puede considerarse el mapa de la frontera de Castilla con Portugal que se conserva en la sección de Mapas, Planos y Dibujos del Archivo General de Simancas ${ }^{30}$. En él se representan los

24 En 1780, durante la reunión celebrada en Badajoz por los administradores generales de rentas de los partidos de la Provincia de Extremadura, el día 22 de mayo de 1780, los presentes llegaron a varias conclusiones sobre la situación de las rentas y lo ineficaz que se había mostrado el resguardo establecido siguiendo las normas dictadas por Bernardo de Ricarte. En la segunda parte del informe que redactaron estipularon los medios que estimaban oportunos para contener tan visibles daños. AGS, Secretaría y Superintendencia de Hacienda (SSH), 2.235. Informe de 17/6/ 1780.

25 AGS, DGR. $2^{a} r, 495$.

26 Biblioteca Municipal de Olivenza, s.c y s.f.

27 La noticia procede de un documento incluido por L. DUARTE INSÚA en su Historia de Alburquerque. Badajoz, 1929, pp. 455-466.

28 Los conceptos de contigüidad los he tomado de NORDMAN, D.: "La frontière: notions et problèmes...", pp. 19-30.

29 BN, Ms. 19.711, no 3 .

30 AGS, Mapas, Planos y Dibujos, XXXVIII-90. "Mapa de la raia de Portugal que comprende los pueblos de los dos Reinos por la parte de Castilla, con la distinción de caminos reales, veredas que siguen los defraudadores, pueblos de su habitación, los en que cargan géneros en Portugal, almazenes, y estancos de tabaco en aquel Reino, residencia de las Rondas, y nueba colocazión de ellas con atención a las noticias que se prometen" (1755). 
senderos y trochas utilizados por los defraudadores de rentas, los vados de los ríos, los establecimientos en que se abastecían, los lugares donde con mayor frecuencia se producían los fraudes, y los emplazamientos de las rondas de vigilancia.

En la década de los ochenta, para su sorpresa, los responsables del fisco constataron la circunstancia de que la corrupción no se hallaba sólo fuera y al margen del sistema, sino que era en su propio seno donde anidaba y había que combatirla con más ímpetu. La respuesta que dieron las instituciones a esta realidad deformada dependió en gran medida del interés y de la sensibilidad demostrados por los secretarios del Despacho de Hacienda, pero consistió básicamente en desplazar hasta enclaves muy significados en la historia del comercio comisiones depuradoras o encaminadas al arreglo del Resguardo de Rentas. Su finalidad última consistía, en el primer caso, en supervisar las administraciones de rentas generales e incoar expedientes disciplinarios a los empleados que con su actitud laxa favorecían el fraude (Francisco Pérez de Mexía, en Cádiz), mientras que en el segundo los comisionados procedieron a reorganizar el sistema de vigilancia aduanero y eliminar los obstáculos que impedían su correcto funcionamiento (Bernardo de Ricarte en Murcia, Alicante y Reino de Valencia), o completaron esta iniciativa con la persecución de defraudadores (Miguel de Obarrio y Montenegro en Navarra).

La visita que Francisco Pérez de Mexía efectuó a las aduanas de Cádiz en 1785 proporciona una radiografía impagable de los mecanismos destinados a vigilar el tráfico de mercancías y descubre la sociología de los empleados de la Hacienda responsables de estos menesteres ${ }^{31}$. Cuando este eficiente empleado procedió a realizarla, se había informado previamente y documentado de los comportamientos que habían sido denunciados. Mexía actuará con contundencia contra los empleados acusados de prácticas irregulares en la gestión de rentas, a los que sustituirá por otros que había seleccionado y consideraba más aptos para el servicio por su demostrada capacidad y probada integridad. No conforme con la rigurosa depuración a que fue sometida la Aduana de Cádiz, por encargo suyo Antonio Valcárcel el Menor redacta un informe de los procedimientos y subterfugios a que acudían los metedores y extractores de mercancías en la ciudad y su bahía, ya fueran procedentes del comercio europeo o de Indias. En tercer lugar, conocidas las deficiencias intrínsecas que soportaba, reestructura y reubica el Resguardo de Rentas de Cádiz para un mejor seguimiento de los tráficos en las comarcas del suroeste de Andalucía.

En 1786 López de Lerena encargó a Bernardo de Ricarte el arreglo de las aduanas y del Resguardo de Murcia, Alicante y el Reino de Valencia. Su actuación no tuvo el coste personal de la reforma practicada en Cádiz, limitándose a fijar regla-

31 AGS, SSH, 2.314 . 
mentos de administración, crear nuevos puestos, remover a algunos empleados de los que ocupaban, jubilar a otros tantos, reforzar los emplazamientos a través de los que se producía un mayor volumen de fraude, construir nuevas edificaciones y habilitar puertos que antes no lo estaban para la introducción de determinados productos. Un cuerpo específico de planes, reglamentos, instrucciones para los administradores de rentas y resguardos fue concretándose en la segunda mitad de 1786 y primeros meses de 1787, según queda patente entre la documentación que sobre el particular se conserva en el Archivo General de Simancas $^{32}$ y la ya estudiada por otros autores que se han ocupado del tema en el Levante español ${ }^{33}$.

Desde el norte de España, Manuel de Sedano Pérez eleva a Lerena, en julio de 1786, un Informe sobre el estado de la renta del tabaco, en el que explica el contrabando en las localidades del Cordón del Ebro y en Navarra, así como la decadencia en que se encontraba dicha renta, las razones de que así fuera y los remedios que convendría promover para incrementar sus valores ${ }^{34}$. Mayor enjundia reviste el Acuerdo de Vitoria para proceder al arreglo del Resguardo de Rentas suscrito el 15 de diciembre de 1787, a propuesta de Miguel de Obarrio y Montenegro, comisionado para inspeccionar las tablas de Navarra y la renta del tabaco en aquella circunscripción. Después de realizar una minuciosa inspección de cuanto acontecía, y al objeto de coordinar las actuaciones del Resguardo de Navarra con los que actuaban en los territorios colindantes, los reunidos en Vitoria agruparon los efectivos disponibles en cincuenta y dos partidas (siete montadas y cuarenta y cinco de a pie) formadas por un total de trescientos hombres ${ }^{35}$.

En resumen, la conclusión que se desprende del análisis de estas comisiones de carácter fiscal, visitas y reformas, es que permitieron, por un lado, la reestructuración de parte del sistema de administración y vigilancia aduanero -aquella cuyo funcionamiento era más deficiente o donde la corrupción era norma de conducta generalizada entre sus dependientes-, así como un conocimiento más detallado de las demarcaciones fronterizas; por otro, dejaron al descubierto una evidencia que marcaría en lo sucesivo las políticas mercantiles y de orden público, a saber: que el problema de los tráficos ilegales de mercancías desbordaba sobradamente las capacidades de los ministros de rentas y que había llegado el momento de acudir a socorros de mayor entidad y alcance.

32 AGS, SSH, 2.290-2.291.

33 PRADELLS NADAL, J.: "La defensa de la costa valenciana en el siglo XVIII: E1 Resguardo", en BALAGUER, E. Y JIMÉNEZ, E. (Eds.): Ejército, ciencia y sociedad en la España del Antiguo Régimen, Alicante, 1995, pp. 241-270.

34 AGS. SSH, 2.304. Informe remitido por Manuel de Sedano Pérez a López de Lerena, sobre la renta del tabaco en el cordón del Ebro. Soria, 8/7/1786.

35 AGS, SSH, 2.307. 


\section{La dificil y comprometida vigilancia de las fronteras de la marginación}

El tráfico ilegal de mercancías ocupó un lugar de preeminencia en las preocupaciones de los gobernantes del siglo XVIII, desde el instante en que conllevaba la no percepción de cuantiosos ingresos directos e inmediatos que contribuían a sostener la monarquía. Su proliferación y las características que presentaba constituían una auténtica pesadilla para la Hacienda, imposible de superarse con las disposiciones legales encaminadas a contenerlo, por lo que hubo de requerirse la participación de instancias más contundentes de poder, como la milicia. En tan ardua como espinosa tarea se implicaron con desigual resultado los sucesivos titulares que ocuparon la Secretaría del Despacho Universal de Hacienda, de Guerra, y de Gracia y Justicia, que hubieron de realizar incontables equilibrios conceptuales para armonizar su percepción del contrabando con la más parcial que mostraron en todo momento los militares, convencidos aquéllos de que se trataba esencialmente de una cuestión económica, y éstos, por el contrario, de que debía primar su vertiente social, en tanto que semillero de potenciales delincuentes de mayor recorrido que el trazado por los metedores de mercancías a pequeña escala cuya actuación se circunscribía a las comarcas rayanas.

La primera intervención del Ejército en la represión del contrabando de que se tiene noticia en la España borbónica se produjo en los territorios del Cordón del Ebro, en la frontera entre el norte de Castilla y Navarra. Fue tan considerable y escandaloso el incremento del fraude en las localidades de esta demarcación durante el primer tercio del siglo, que Felipe V se vio obligado a enviar en 1733 cuatro destacamentos de caballería para combatir los desmanes que se producían ${ }^{36}$. Con la colaboración de los militares, los dependientes del Resguardo averiguaron la identidad de los defraudadores, los cuales, convencidos de sus delitos o temiendo el castigo, los confesaron y acudieron a la piedad del rey. Obtuvieron su perdón tras comprometerse los habitantes de las localidades de Cervera del Río Alhama, Aguilar, Inestrillas, Navajún y Valdemadera, por escritura de obligación que firmaron el 12 de julio de 1733, “en su nombre y el de sus subcesores, hipotecando a su cumplimiento los vienes y Propios de los pueblos, y de cada vecino en particular, de celarse y aprehenderse unos a otros de no permitir en su territorio defraudadores ni personas sospechosas; de no tener comercio en Francia ni comerciar en cacao, azúcar y demás géneros, pues si alguna vez lo sacavan de Navarra, devía ser con ciertas restricciones, y de sugetarse a las demás reglas que se impusieron y creyeron suficientes a su enmienda" ${ }^{37}$. El compromiso suscrito,

36 ZUAZNAVAR, J.M.: Op. cit., pp. 16-19.

37 Novísima Recopilación, Libro $9^{\circ}$, Título $7^{\circ}$, Auto $5^{\circ}$. 
duró poco ni nada, porque acostumbrados a la vida libre y aficionados al excesivo lucro que el fraude les rendía, formaron nuevas compañías y volvieron a extraer considerables porciones de pesos fuertes, y a introducir toda clase de géneros, sin que el Resguardo pudiese oponerse a sus quadrillas de sesenta y más hombres armados, de modo que haciendo ilusorias por su tierra y unión las providencias que se davan, vivían con escándalo del reino, cometiendo quantas maldades son imaginables, pues siendo su menor delito el contravando, sin respeto a la Justicia, hacían robos y muertes, eran incendiarios y tumultuaban los pueblos ${ }^{38}$.

En el caso de la población extremeña de Ceclavín, próxima a la frontera con Portugal, puede afirmarse que lo sucedido el 15 de enero de 1755 cambiaría, de modo decisivo, la historia del contrabando e introduciría modificaciones sustanciales en la forma en que las autoridades entendían esta práctica y en la consideración de los contrabandistas. En esta ocasión, el tumulto se desencadenó a raíz de una circunstancia que en los territorios limítrofes solía ser habitual, cual era el registro de las casas en que se sospechara existían mercancías de contrabando, bien porque hubiera precedido una delación, o porque se tratara de conocidos defraudadores. La reacción inmediata de los vecinos desembocó en una revuelta que obligó a evacuar del lugar, bajo sagrado, a los guardas de rentas. Al poco del tumulto, Fernando VI nombró a Bernabé de Armendáriz y Álvarez de Eulate, mariscal de campo y gobernador militar y político de la villa de Alcántara, como comisionado militar para reprimir estos sucesos, poniendo bajo su mando un contingente de 1.300 soldados que ocuparon la población, con todo lo que esto conllevaba y las obligaciones que comportaba para los vecinos ${ }^{39}$. Sin embargo, tras unos meses de frenética actividad para intentar descubrir a los culpables del amotinamiento y dictar sentencia, la muerte sorprendería al comisionado en la tarde del día 26 de julio de 1755 . Una repentina dolencia, achacada a los calores del verano, se complicaba con una hemorragia interior para llevarle de este mundo. Fallecía sin concluir el cometido que se le había encomendado y sin culminar con éxito ninguno de los proyectos reformadores que había intentado sacar adelante para corregir los vicios de los ceclavineros. Pese a tan corta experiencia en este terreno, se sentaban algunos de los pilares y directrices que inspirarían el desarrollo de las comisiones militares promovidas por Carlos III y Carlos IV para la persecución de contrabandistas y de toda clase de delincuentes ${ }^{40}$.

Con posterioridad a estos episodios, la Instrucción de 29 de junio de 1784 se convertiría en la base sobre la que se levantó la persecución del contrabando y la de-

38 AGS, SSH, 2.306. Informe al secretario del Despacho de Hacienda. Madrid, 14/1/1794.

39 AGS, SSH, 1.060. Escrito de 23/I/1755.

40 Los pormenores de todo lo acaecido se detallan en MELÓN, M.A.: Hacienda, comercio y contrabando en la frontera de Portugal (siglos XV-XVIII), Cáceres, 1999, pp. 193-230. 
lincuencia a finales del Antiguo Régimen. Empeño personal de Miguel de Múzquiz, pero cuya aplicación recayó por entero en Pedro López de Lerena, en el preámbulo de la normativa se hacía mención expresa de un incremento de la delincuencia que aconsejaba tomar medidas urgentes. Para combatirla se comisionaba a los capitanes y comandantes generales de provincias, esperando que actuaran con "el vigor correspondiente a la profesión militar" ${ }^{41}$. En el apartado XVII se establecía expresamente que,

Los Capitanes Generales que confinen con reino extraño, a más del cuidado común a los demás de perseguir los facinerosos y contrabandistas según va referido, lo tendrán continuo y muy particular en cubrir todos los caminos, veredas y territorios de su frontera con el tal reino extraño, a fin que no pase contrabando ni persona alguna sin ser reconocida, y arrestada en caso de que su porte y señas den alguna sospecha.

Esta medida supone un salto cualitativo de enorme trascendencia y no ponderado en su plena extensión por los promotores, en cuanto a los modos de reprimir los delitos que solían ser habituales en las sociedades de Antiguo Régimen. En principio, acudir al Ejército significaba encomendar labores de policía, propias de tiempos de paz, a gentes formadas y entrenadas para la guerra, cuyo cursus honorum adquiría en tal situación extrema su sentido pleno. Por otro lado, al reconocerse explícitamente la posibilidad de juzgar a los reos en consejo de guerra, se estaba acudiendo a una justicia de excepción que convertía a los militares en policías y jueces a un tiempo con capacidad decisoria sobre delitos que no eran de su incumbencia ni se contemplaban dentro del Código de Justicia Militar. En tercer lugar, en su calidad de cuerpos policiales, ejercerían un control del territorio que hasta entonces sólo habían practicado desde el punto de vista de la defensa. Esta medida supuso un importante avance en cuanto a la monopolización de la fuerza y al uso que de ella hacía el Estado Absoluto, pero también propició una distorsión del orden establecido, en tanto en cuanto surgieron las inevitables interferencias entre poderes, desde el instante en que se sacó al Ejército de los cuarteles para resolver problemas de tipo civil. La gravedad de las circunstancias, el estado de necesidad, evitó a los responsables ministeriales de estas decisiones la elaboración de un discurso justificativo que legitimara las atribuciones que se les conferían y que eran ajenas al fuero militar.

41 Colección de todas las instrucciones generales y particulares, Reales órdenes y declaraciones mandadas expedir y observar para la persecución y aprehensión de ladrones, contrabandistas, desertores, vagos y toda clase de malhechores en todo el Reyno, comunicadas por la Suprema Junta de Estado y Ministerios de Gracia y Justicia, Guerra y Hacienda a los Capitanes Generales, Chancillerias, Audiencias, Intendentes, Juntas principales Provinciales de Rentas Reales, Gobernadores, Corregidores y Justicias ordinarias. Plasencia. De orden superior. 1801. 
Junto con la instrucción se envió a los capitanes generales un oficio donde figuraba el siguiente encabezamiento: "El rey quiere que se exterminen las quadrillas de malhechores y contrabandistas que de algún tiempo a esta parte infestan el reyno con grave perjuicio del Estado y de sus amados vasallos; y a este fin, ha mandado extender la adjunta instrucción para perseguir a viva fuerza tales delincuentes y que se proceda con igual vigor y actividad en todas partes hasta lograr su total extinción" 42 . Los militares podrían valerse de los medios que estimaran oportunos "para perseguir y exterminar en todos los caminos y distritos de la comprensión de su mando una gente tan perjudicial al público"43. Cuatro años más tarde, por instrucción de 24 de septiembre de 1788, Carlos III solicitaba información de las actuaciones y medidas puestas en marcha por las capitanías generales desde 1784 en esta dirección; requerimiento al que respondieron con desigual criterio y efectividad, pero de las cuales se deduce el mosaico de situaciones que regía las prácticas fraudulentas en las fronteras de Portugal, Francia y Gibraltar ${ }^{44}$.

La instrucción de junio de 1784 se completó con la creación de varias comisiones militares integradas por soldados y contrabandistas arrepentidos, que se convertirían en transitoria garantía de la integridad y los intereses de los vecinos ante los abusos que defraudadores y facinerosos cometían a diario. La más importante y principal, por ser la que de más medios dispuso, mayor capacidad operativa tuvo y mejores resultados consiguió, fue la encargada a Juan de Ortiz y Borja, coronel agregado al Batallón de Voluntarios de Aragón, que fue comisionado en 1784 por Carlos III para que celase en Andalucía "sobre el exterminio de tantos delincuentes por quantos medios fuesen condusentes hasta conseguirlo y asegurar la quietud de estas provinsias y restablesimiento de la real renta del tabaco"45. Personaje de recto proceder, su primer encargo se prolongó hasta 1789 y contó con la protección de López de Lerena, figura central en lo acaecido durante el desarrollo del encargo y en el modo de sustanciarse tan prolijo como documentado proceso. De él se conservan los informes que el militar elaboró sobre el contrabando, sus practicantes, sus rutas, y las medidas que concibió para erradicarlo; las tropas y medios que empleó y los partes de sus actuaciones; los problemas de intendencia a que hubo de hacer frente; los obstáculos insalvables que encontró entre sus compañeros de armas, así como en

42 AGS, Guerra Moderna (GM), 4.245. Madrid, 11/7/1784. PALOP RAMOS, J.M.: "La militarización del orden público a finales del reinado de Carlos III. La Instrucción de 1784", Revista de Historia Moderna, 22, 2004, pp. 453-486.

43 AGS. GM, 4.245. Madrid, 11/7/1784.

44 AGS. GM, 4.252: "Sobre noticias reservadas pedidas a los Capitanes Generales en asunto de auxilio para persecución de contrabandistas, 1788". Los detalles del proceso que se desencadena a partir de promulgarse esta legislación aparecen recogidos en MELÓN, M.A.: Los tentáculos de la Hidra. Contrabando y militarización del orden público en España (1784-1800), Madrid, 1999.

45 AGS, SSH, 2.296. Lucena, 15/4/1789. 
las justicias, los eclesiásticos, las autoridades locales y las oligarquías de los municipios que sometió a vigilancia; finalmente, su expedición a la frontera de Extremadura con Portugal en el verano de 1786 y los asuntos que allí ventiló y que le permitieron captar las diferencias sustanciales entre los habitantes de las provincias que, por exigencias del servicio, le había cabido en suerte recorrer.

El 26 de mayo de 1784 dirigía Juan de Ortiz a Lerena un Informe razonado sobre el contrabando en el que sintetizaba sus primeras impresiones, desvelaba el mecanismo que lo soportaba y pormenorizaba los resortes que encubrían un fraude en el que aparecían implicados representantes de todas las clases sociales. Sitúa su epicentro y enumera los que serían los enclaves más activos, que se ubican en las comarcas de la Subbética cordobesa y de Antequera, y define una espiral que, arrancando de Encinas Reales, Cuevas Altas y Cuevas Bajas, proyecta sus ramificaciones hasta situar en círculos casi equidistantes de ellas a los principales núcleos urbanos: de Granada a Sevilla, de Córdoba a Jaén, y de Cádiz a Málaga. En un segundo Informe, fechado el 17 de julio de 1784, adelanta las dificultades que advertía para el cumplimiento de su comisión y detalla la geografía y la sociología del contrabando que había que perseguir, así como las redes montadas por los defraudadores para llevarlo a cabo.

Dado que el problema no se solucionaría exclusivamente con medidas de carácter militar, y que las puestas en práctica generaban mayores problemas que soluciones, de 1788 a 1792 la Junta Suprema de Estado, presidida por Floridablanca, abordó en veinticinco sesiones el espinoso tema del contrabando. El asunto suscitó un intenso debate el 5 de julio de 1790, reunión en la que Antonio Porlier, Secretario del Despacho de Gracia y Justicia de Indias, leyó el contenido de una serie de Representaciones sobre el deplorable estado al que contrabandistas y facinerosos tenían reducida a Andalucía. Floridablanca remitió copia de las representaciones al presidente de la Chancillería de Granada, al asistente de Sevilla, a los corregidores de Gibraltar, Jerez de la Frontera, Hoya de Málaga, Lucena y Córdoba, y a los alcaldes mayores de Málaga, Antequera y Écija para que informaran de los hechos que en ellas constaban y para que facilitaran las noticias que hubieran adquirido, que acompañarían, si fuera posible, de documentos que acreditasen su certeza, como cartas de los ayuntamientos, alcaldes o párrocos. Las respuestas a esta petición son unánimes: no hay informe del casi centenar que se remitieron "que no haga una pintura mui lastimosa de las Andalucías respecto a los contravandistas y malhechores de que se hallan inundadas por todas partes y de los daños y perjuicios que reciben los vecinos honrados"46.

Las comisiones militares habilitadas por Carlos IV tras las mencionadas deliberaciones de la Junta Suprema de Estado recayeron sobre Domingo Mariano Tra-

46 AGS, SSH, 2.303. Diversos expedientes. 
ggia (1789-1797), marqués del Palacio, en la frontera de Castilla con Navarra, y en Pedro de Buck y O’Donell (1791-1794) y Juan de Ortiz (1794-1800) en Andalucía y Extremadura. Guardan entre sí notables diferencias dimanadas de las actitudes de sus responsables y de los métodos empleados en la persecución de defraudadores y facinerosos, así como de las características específicas con las que se manifiestan el contrabando y la delincuencia en las zonas a las que fueron destinados. La información que generan es, no obstante, de menor calado que la reunida durante la primera fase de las comisiones militares, si bien algunos de los expedientes, como el referido a Andalucía redactado por el coronel de dragones Pedro de Buck y remitido al conde de Campo Alange, en noviembre de 1791, se distancia de la óptica cuartelera que solía ser habitual en ellos y advierte sobre las causas del problema desde la perspectiva de un militar ilustrado y reformista, convencido de que sólo podía finiquitarse acudiendo a "una política mui fina y un pulso mui delicado", si se querían llevar a buen puerto los dos encargos que el rey le había encomendado: procurar el aumento de las rentas estancadas y de aduanas y atender la seguridad pública. La sociología del entramado que se presentaba ante sus ojos debió proporcionarle una enorme inquietud a este fiel servidor del Trono:

El contravando, Sr. Excmo., en estos reinos, puede considerarse como un aire contagioso del que no se libertan sino ciertas personas pribilegiadas por algún secreto particular de la naturaleza, o por gracia especial de la divina misericordia. Los clérigos, los frailes y los poderosos están tocados de este aire pestilente; algún juez, algún ministro de rentas también están infectos; hai pueblos enteros que se hallan corrompidos, y son mui pocos en donde ya no haia hecho estragos este cáncer del Estado ${ }^{47}$.

En el primer Informe que Domingo Mariano Traggia remitió a sus superiores desde su destino en Cervera del Río Alhama, identificaba a los vecinos dedicados a la extracción de monedas con destino a Francia, vía Navarra; daba cuenta de los proyectos y reformas que concibió e impulsó, así como de la estratagema que puso en marcha para organizar una saca ficticia de monedas haciéndose pasar por un contrabandista. En la correspondencia que mantiene como señuelo con sus interlocutores, un judío de Bayona y la firma Goyeneche Hermanos, de San Juan de Pie de Puerto, se detallan los procedimientos que utilizaban los defraudadores, las rutas y los pasos que frecuentaban, los pueblos y los receptadores de las mercancías, las contraseñas, y la cobertura legal que proporcionaban "respetables" casas de comercio y de banca de

47 AGS, SSH. 2.303, Informe de Pedro de Buck sobre el contrabando en Andalucía. Écija, $9 / 11 / 1791$. 
Pamplona y comerciantes de uno y otro lado de los Pirineos. Lo cual no es pequeño bagaje para el conocimiento de lo que verdaderamente ocurría en las tierras altas de Castilla y en la frontera pirenaica.

\begin{abstract}
Bien recelo que más de sesenta casas de comercio de Vizcaya i Navarra que se han mezclado en los ilícitos manejos de los cerveranos, en especial de los reconocidos por espacio de quarenta i más años, la complicación con algunas graves personas, i el valimiento de otras mal informadas, pueden haver influido mucho hasta aquí en el retardo de las providencias precisas. Pero no se oculta a la alta penetración de V.E. que, si los pueblos del río Alhama han de dejar en adelante de defraudar las rentas i patrimonio real de S.M. con el abandono que solían hacerlo i constituirse útiles i quietos vecinos, es necesario sobre la violencia primera para ellos desagradar a los que lucran i han lucrado con su antiguo modo de vivir; i tales son precisamente las casas de Navarra i Vizcaya que les ayudan en sus fraudes ${ }^{48}$.
\end{abstract}

El Ejército compartió durante este tiempo tareas de vigilancia con otros cuerpos de milicia, como las Compañías de Milicia Honrada, en Galicia; los Mossos d'Esquadra, las Rondas Volantes Extraordinarias y la Compañía Fija de Rosas, en Cataluña; la Compañía Suelta de Fusileros y el Batallón de Voluntarios, en Aragón; los Migueletes o Miñones valencianos; las Compañías de Infantería Fija de la Costa de Granada, los Escopeteros de Getares, la Real Maestranza de Ronda, y los Escopeteros Voluntarios de Andalucía. Todos ellos aportaron cumplida información sobre los tipos de delincuencia que se les ordenó perseguir y sobre los territorios en que lo hicieron.

Ha de subrayarse también el interés, el compromiso y la solvencia demostrados por las instituciones de la administración de Justicia en la persecución del contrabando y la delincuencia. En primer lugar, por las Chancillerías de Valladolid y Granada, muy comprometidas con las tareas de orden público en sus respectivas demarcaciones; también por las audiencias provinciales, como la de Extremadura, que desde su creación dedicó una atención preferente a los partidos limítrofes de su jurisdicción. Producto de esta actitud fueron los informes elaborados sobre los de Badajoz, Llerena, Alcántara y Coria, en los que pormenorizaron los peculiares modos de vida de sus habitantes. Son muy ilustrativas las "Observaziones de los confines de Portugal al Partido de Coria" realizadas por el oidor Francisco Javier de Contreras, en respuesta a la Instrucción reservada del Consejo de Castilla a que debían atenerse durante la Visita de la Provincia de Extremadura en 1790, previa al establecimiento en ella de su Real Audiencia. En primer lugar, los comisionados judiciales de los partidos confinantes con el reino de Portugal debían “entrar en los pueblos comarcanos de él e informarse de lo que allí se

48 AGS, SSH, 2.306. Marqués del Palacio a Pedro de Varela y Ulloa. Cervera, 4/11/1796. 
observa en la labranza, crianza de ganados, quinterías, dehesas y plantíos, anotándolo todo para que sirva de instrucción lo que convenga imitar"; procederían "conduciéndose los ministros con prudencia en la adquisición de tales noticias para no excitar emulaciones", y tomarían buena nota de las prácticas fraudulentas a que incitaba "el cuidadoso comercio que hacen los portugueses sobre nuestras fronteras"49.

Fueron motivo de un meticuloso análisis las poblaciones de Salvatierra do Extremo, Segura, Rosmariñal, Monfortiño, Peñagarcía, La Cebrera, Alcafoçes, Los Fulones, Monsanto, y Castelobranco, así como los modos de vivir sus habitantes y sus formas de gobierno. El avezado encuestador recabó cuantas noticias le fueron ofrecidas por "personas prácticas de integridad y noción segura", a propósito del inveterado vicio del contrabando, las causas de su proliferación, las técnicas empleadas por los defraudadores, el destino final de las mercancías que introducían - "lo interior del Reyno en la Corte y pueblos de magnitud"- y el estrato sociológico al que pertenecían sus practicantes, entre los que ocupaban un lugar destacado los "albergados forasteros españoles criminosos" residentes en los pueblos fronterizos y aplicados a estas prácticas, bien asociados entre sí, o con la colaboración de personas respetables que en las localidades rayanas participaban en las redes fraudulentas que desplegaban desde ellas sus tentáculos hacia las regiones del interior de España.

\section{Consideraciones finales}

Con independencia de los resultados obtenidos en la gestión de las fronteras del comercio y de la marginación, es evidente que se produjo un cambio de actitud en la consideración de estos espacios por parte de los administradores de rentas y de los responsables de mantener el orden en la España del siglo XVIII. Prueba del interés suscitado es que comenzaron a regirse con una información precisa y a vigilarse con pulso más firme que en época de los Austrias, por lo que no se dudó en acudir a casi todos los medios al alcance del Estado y a los instrumentos de que disponía para garantizar el orden en sus contornos. Bien es verdad que no se consiguió terminar con el fraude -consustancial al propio sistema y en algunas circunstancias elemento corrector de las carencias que éste padecía- ni erradicar la violencia; que el control no resultó tan eficaz como se pretendía, a pesar del elevado número de agentes destinados a impermeabilizarlas; o que el coste social fue bastante más elevado de lo que los reformadores hubieran querido, como demuestran las numerosas condenas que se impusieron por delitos de contrabando y resistencia armada frente a los dependientes del Resguardo de Rentas y al Ejército, pero lo cierto es que las fronteras pasaron de

49 Archivo Histórico Provincia de Cáceres (AHPCC), Real Audiencia de Extremadura, 10, expte. 31. 
ser un elemento marginal y secundario en las preocupaciones de los gobernantes, a ocupar un primer plano, tanto en términos fiscales como en materia de seguridad pública, lo que contribuyó a su mejor definición y a un más estrecho seguimiento que cuando apenas se percibían como un territorio hostil y marcado casi exclusivamente en términos bélicos por los emplazamientos militares que la jalonaban.

Las conclusiones de lo expuesto se orientan en dos direcciones claramente definidas. Por un lado, la reestructuración administrativa de que fue objeto permite una aproximación a los aspectos organizativos de la frontera y a lo que allí ocurría a la vista de todos; los materiales recopilados a partir de 1784 facilitan, por el contrario, una aproximación a su cara oculta, aquella que no aparecía en los itinerarios y en las anotaciones de los viajeros, pero sí en los sobrios testimonios de quienes tuvieron a su cargo perseguir las conductas delictivas de algunos de los sujetos que la habitaban. El intento de homogeneizar estos territorios y la aplicación de una política de signo proteccionista provocó el efecto indeseado de un incremento del contrabando, tanto marítimo como terrestre, lo que hizo que aflorara la diversidad de situaciones y conductas que propiciaba y escondía en su seno.

Aunque tiende a serlo, la frontera no es necesariamente un área de confrontación perpetua y la militarización de su entorno es una de las respuestas posibles, la más contundente, sin duda, como se vio a finales del Antiguo Régimen, pero a la que se acudió sólo en caso de extrema necesidad. De los informes elaborados por los jefes del Ejército en sus demarcaciones emergen los trazos de una identidad fronteriza, compleja y difícil de definir como todas las de frontera, por aparecer a menudo dividida y lacerada entre el diálogo y el ajuste de cuentas ${ }^{50}$, pero claramente diferenciada, como tuvieron ocasión de comprobar los capitanes generales Pedro Martín Cermeño en Galicia, el conde de Campo Alange en las Provincias exentas limítrofes con Francia, el vizconde de Palazuelo en Navarra, Félix Oneille en Aragón, el Conde de Asalto en Cataluña, Luis de Nieulant en Castilla la Vieja, José de Veciana en Andalucía, o el marqués de Casa Cajigal en Extremadura. Ese perfil, repleto de matices que configuran una parte sustancial del modo de ser fronterizo, incluso en sus extremos más excesivos, emerge asimismo de las anotaciones realizadas por los comisionados en las respectivas zonas que se les encomendó vigilar. Así ocurre con los memorandos de Juan de Ortiz sobre Andalucía y Extremadura, con los remitidos por las autoridades locales y provinciales a la Junta Suprema de Estado, con el minucioso que salió de la pluma de Pedro de Buck durante su comisión, o con el retrato que Domingo Mariano Traggia plasma de Castilla, Navarra y el Cordón del Ebro. Por no aludir a lo que encontró en Cádiz Francisco Pérez de Mexía al aplicar con decisión y contun-

50 MAGRIS, C.: El Danubio, Barcelona, 2009, p. 76. 
dencia el bisturí que le permitió cortar de raíz -temporalmente al menos- la gangrena que provocaban en el fisco las conductas desviadas en que incurrían los aduaneros.

Ha de tenerse presente asimismo que, en la interacción que se sucede de continuo entre fuerzas centrales y periféricas, en el feedback a que aludía, los concejos fronterizos, dominados por unas oligarquías cuyos atributos, resortes y estrategias no siempre coinciden con los utilizados y reconocidos como propios por los grupos tradicionales que detentaban el poder, desempeñan un papel primordial. Les corresponde a ellos, en primera instancia, sobre el terreno y en la inmediatez de lo cotidiano, articular el espacio, salvaguardar el orden, regular las actividades económicas, y encontrar fórmulas que garanticen la estabilidad en zonas poco propensas a observarla o agitadas de continuo. Tareas que los estados en vías de constitución suelen dejar en manos de estas comunidades para que sean ellas las encargadas de asegurar la convivencia, con los correspondientes riesgos que comportan la familiaridad y los lazos de parentesco de los vecinos con las autoridades. Estos concejos constituyen la primera y a la vez última línea defensiva de que disponen las monarquías en los territorios fronterizos, a raíz de lo cual se ven sometidos circunstancialmente a una presión extrema cuando los gobiernos deciden prescindir de negociaciones y continuar la diplomacia por otros medios. Y es precisamente sobre ese estado de inquietud latente propiciado por el miedo casi atávico entre colectividades vecinas, separadas a menudo por marcas artificiales cuya razón de ser se les escapa, donde descansa un conjunto de comportamientos colectivos en los que es posible entrever el verdadero murmullo de fondo de la frontera, opuesto casi siempre a cualquier intento que desde el exterior pretendiera introducir alguna clase de racionalidad que no fuera consustancial a las prácticas socioeconómicas que la línea de confluencia entre dos reinos fue moldeando durante siglos.

Emerge entonces un componente sociológico solidario que contribuye a definir la personalidad de las gentes que habitaban los espacios periféricos que contribuía como ningún otro a preservar el status quo de las comunidades fronterizas. Porque la frontera, además de muchas otras cosas, es esa tierra de nadie donde todos, tarde o temprano, hallan su sitio, y donde encuentran acomodo cuantos se dirigen a ella buscando un lugar seguro de acogida en el que apenas nadie pregunta nada, porque buena parte de quienes la pueblan tienen a menudo mucho que ocultar. Bien de manera inmediata, o con el paso del tiempo, tales actitudes de complicidad permiten configurar unos apoyos y socorros mutuos, inconcebibles en otros lugares y difíciles de extirpar cuando se perseguían conductas que escapaban de la norma y la moral establecidas. Se trataba, como se vio en Cervera del Río Alhama (1733), en Ceclavín (1755), y en las localidades andaluzas que tenían en la frontera portuguesa y gibraltareña sus tratos, de una reacción que galvanizaba complicidades y establecía lazos 
imposibles de deshacer, producto de la fuerte sensibilidad ante el peligro o la amenaza externa que podía romper con un modo de vida. Esta actitud defensiva contribuye como ninguna otra a dar forma y a afianzar una identidad territorial en la que los fenómenos de exclusión apenas si son perceptibles -o lo son en menor medida-, al actuar como área de acogida de una porción considerable de los marginados sociales que generan la políticas de diferenciación de diverso signo promovidas por las autoridades del Antiguo Régimen. Nadie resultaba ni podía sentirse extraño en un mundo al que muchos habían sido obligados a acogerse, o en el que desde su seno habían optado por soluciones al margen de la ley para compensar sus carencias vitales.

Semejante actitud variaba, sin embargo, dependiendo del tipo de actividades que se considerara. Por encima de decisiones políticas y cuestiones de Estado, la percepción de la frontera por sus moradores se modificará en función de determinados factores, asumiendo durante la Edad Moderna connotaciones hostiles cuando de aprovechamientos agropecuarios se trate, como lo demuestra la relación de agresiones que por este motivo trasladan el 1 de diciembre de 1779 el alcalde y los regidores de Navasfrías al intendente de Ciudad Rodrigo; una prueba, entre muchas otras, de los conflictos que por estos motivos se originaban ${ }^{51}$. Por el contrario, siempre que mediaran intereses comerciales (Cervera del Río Alhama, Ceclavín), los comportamientos solidarios hacían acto de presencia y desarrollaban un entendimiento y socorro mutuos, imposibles de sortearse por las autoridades de ambos lados, ya fuera en la frontera pirenaica o en la portuguesa.

Sólo en un contexto de amenaza de ruptura de prácticas ancestrales, como ocurrió al pretender racionalizar lo imposible, se desencadenarán movimientos de protesta espontáneos y alejados de las pautas y la secuencia lógica consustancial a las alteraciones sobrevenidas en fases concretas del Antiguo Régimen. De norte a sur, los ingobernables personajes que pululaban por la periferia territorial del Estado abortaron cualquier proyecto encaminado a imponer unas mínimas pautas de cordura en sus economías, ya fuera mediante las medidas reformadoras sugeridas por Armendáriz en la frontera con Portugal, o por Traggia para las localidades del Alhama: valía más preservar lo conseguido, que precipitarse hacia una contestación que pudiera trastocar las bases socioeconómicas sobre las que descansaba aquel mundo. Es en esa tesitura "quand la frontière, au sens ancien et toujours latent du mot, devient o redevient le lieu d'une forte sensibilicé aux dangers, c'est là que s'elabore l'idée, plus

51 Archivo Histórico Nacional (AHN), Consejos, 981. El lugar, perteneciente a la encomienda de Eljas, de la Orden de Alcántara, lo poblaban 60 vecinos, "la maior parte de ellos naturales del Reyno de Portugal", y había sido entre 1756 y 1779 objeto de las iras y de toda clase de atropellos por parte de los habitantes que residían en el lado luso de la frontera. 
vigoureuse que jamais, de l'identité territoriale" 52 . En sus carnes experimentaron los dependientes de rentas y los militares las consecuencias inmediatas de los comportamientos provocados por este tipo de actitudes. Una lectura atenta a la documentación descubre infinidad de testimonios e historias de vida que emanan de la aplicación de esta premisa y alumbran perfiles hasta ahora no suficientemente considerados, cuyos arquetipos contribuyeron, en gran medida, a modelar la imagen deformada que de España se impuso en el extranjero a partir del siglo XIX.

La conceptualización y el análisis de la frontera deben, en último término, aspirar a la totalidad, para intentar desde ella articular una serie de categorías que posibiliten la comprensión del aparente desorden con que actúan y se manifiestan las múltiples variables que en ella confluyen. Sin que tal premisa suponga prescindir de los detalles efímeros que, por su singularidad, han contribuido a definir su historia, ha de admitirse igualmente que su percepción variará, conforme al punto de vista que se contemple y la finalidad que se persiga. La captación de esa totalidad, entendida en sus complejas manifestaciones, debe conducir a la necesaria comprensión de conjunto, sin que tal presupuesto comporte una renuncia expresa a la fragmentariedad que la individualiza y cuyos detalles, por irrepetibles, ayudan a explicar el devenir cotidiano de los súbditos que poblaron en el pasado los márgenes territoriales de los Estados soberanos. La argamasa resultante contribuirá a fijar los aspectos metodológicos de una Historia de la Frontera a lo largo de los siglos, "una historia de desorden pero también de disciplina, del férreo vínculo que unía a estas gentes, cuya patria era una tierra de nadie entre las patrias ajenas" e inspirada bajo los auspicios de una altiva autonomía y de la "celosa tutela de su propia independencia ante cualquier autoridad externa" 53 .

El tratamiento y consiguiente interpretación de la ingente cantidad de información que fluye durante el siglo XVIII desde la Administración central hacia estos territorios, y desde éstos hacia aquélla, requiere, por último, y dada la variedad de materiales referidos a unas zonas muy concretas, de una propuesta interdisciplinar capaz de arrojar luz sobre el crisol de componentes del más diverso signo que allí concurren. Una propuesta que permita desarrollar un cuerpo conceptual sólido sobre la frontera; que englobe las diferentes dinámicas que se encuentran en ella y contribuya a explicar los comportamientos y las actitudes de sus pobladores; que aúne aportaciones provenientes de diversas disciplinas, si se pretende dar respuesta a las múltiples facetas que la integran y a los mundos que en ella confluyen. La concurrencia de estas variables permitirá abordar con garantías de éxito las sugestivas perspectivas

52 NORDMAN, D.: “La frontière: notions et problèmes...", pp. 19-30.

53 MAGRIS, C.: Op. cit., p. 301. 
de análisis que dimanan de la aproximación a unos espacios en los que se ha escrito -y escribe a diario- una parte sustancial de la historia del mundo, no precisamente la más edificante a veces, pero sí a menudo la más decisiva, y cuyas dimensiones historiográficas han de construirse en términos, primero, europeos, y después, mundiales. A esa empresa, de dimensiones colosales, pero irrenunciable, están convocados especialistas del mundo del Derecho, de la Historia económica, la Historia social, la Historia cultural, la Historia militar, la Geografía, la Sociología, o la Antropología. He ahí la encrucijada que se presenta ante nosotros, los historiadores, y la necesidad de proceder a la necesaria síntesis que aglutine las aportaciones sectoriales que desde distintos países y ámbitos, a uno y otro lado del Atlántico, han venido sucediéndose en los últimos años. Los trabajos de D. Norman citados, así como los de P. Sahlins, D. Power y N. Standen, J.F. Bannon, W.J. Eccles, R.D. Hurt, A. Pastore, o B.A. Raviola, entre otros, apuntan en esa dirección y marcan las pautas metodológicas que habrán de seguirse en el futuro ${ }^{54}$.

54 SAHLINS, P.: Fronteres i identitats: la formació d'Espanya i França a la Cerdanya, s. XVII$X I X$, Vic, 1993, y "Natural frontiers Revisited: France's Boundaries since the Seventeenth Century", American Historical Review, 95, 1990, pp. 1.423-1.451; POWER, D. y STANDEN, N. (Eds.): Frontiers in question. Eurasian Bordelans, 700-1700, Londres, 1999; BANNON, J.F.: The Spanish Borderlands Frontier, 1513-1821, Albuquerque (NM), 2001; ECCLES, W.J.: The Canadian Frontier, 1534-1760. Albuquerque (NM), 1983; HURT, R.D.: The Indian Frontier, 1763-1846, Albuquerque (NM), 2002; PASTORE, A.: Confini e frontiere nell'età moderna. Un confronto fra discipline, Atti del seminario, Garghano, 22-23 aprile 2005, Milano, 2007; RAVIOLA, B.A. (Ed.): Lo spazio sabaudo. Intersezioni, frontiere e confini in età moderna, Milano, 2007, y Cartografia del Monferrato. Geografia, spazi interni e confini in un piccolo Stato italiano tra Medioevo e Ottocento, Milano, 2007. 